Published in final edited form as:

Attach Hum Dev. 2013 ; 15(4): 384-406. doi:10.1080/14616734.2013.768790.

\title{
Molecular-genetic correlates of infant attachment: A cautionary tale
}

\author{
Glenn I. Roisman ${ }^{\mathrm{a}}$, Cathryn Booth-Laforce ${ }^{\mathrm{b}}$, Jay Belsky ${ }^{\mathrm{c}, \mathrm{d}, \mathrm{e}}$, Keith B. Burt ${ }^{\mathrm{f}}$, and Ashley M. \\ Groh 9 \\ Glenn I. Roisman: roism001@umn.edu \\ aUniversity of Minnesota, Minneapolis, MN, USA \\ bUniversity of Washington, Seattle, WA, USA \\ 'University of California, Davis, CA, USA \\ 'King Abdulaziz University, Jeddah, Saudi Arabia \\ eBirkbeck University of London, London, UK \\ fUniversity of Vermont, Burlington, VT, USA \\ gUniversity of North Carolina at Chapel Hill, Chapel Hill, NC, USA
}

\begin{abstract}
This paper advises caution in relation to the increasing interest in molecular-genetic association studies in developmental psychology based on a set of empirical examples from the NICHD Study of Early Child Care and Youth Development (SECCYD) that highlight the fragility of effects reported in the literature on the molecular-genetic correlates of infant attachment. Specifically, this paper updates and provides three extensions to results reported in Luijk et al. (2011), which recently failed to replicate evidence from smaller-sample studies that a set of dopaminergic, serotonergic, and oxytonergic markers are significantly associated with infant attachment security or disorganization. First, we report here that the average effect of "usual suspect" polymorphisms on infant attachment security and disorganization in the SECCYD is approximately zero. Second, because Luijk et al. (2011) reported data based exclusively on the White infants in the SECCYD, this paper reveals that the average effect of polymorphisms featured in this literature is also of trivial magnitude in the non-White sub-sample (cf. Chen, Barth, Johnson, Gotlib, \& Johnson, 2011). Third, this paper attempts, but fails, to replicate a recent finding by Raby et al. (2012) suggesting that, although molecular-genetic polymorphisms might not be implicated in security versus insecurity, the serotonin transporter gene contributes to variation in emotional distress
\end{abstract}

\footnotetext{
(C) 2013 Taylor \& Francis

Correspondence to: Glenn I. Roisman, roism001@umn . edu.

Publisher's Disclaimer: Full terms and conditions of use: http://www.tandfonline.com/page/terms-andconditions

This article may be used for research, teaching, and private study purposes. Any substantial or systematic reproduction, redistribution, reselling, loan, sub-licensing, systematic supply, or distribution in any form to anyone is expressly forbidden.

The publisher does not give any warranty express or implied or make any representation that the contents will be complete or accurate or up to date. The accuracy of any instructions, formulae, and drug doses should be independently verified with primary sources. The publisher shall not be liable for any loss, actions, claims, proceedings, demand, or costs or damages whatsoever or howsoever caused arising directly or indirectly in connection with or arising out of the use of this material.
} 
during the Strange Situation Procedure. Implications for future research on the genetics of developmental phenotypes in general and attachment in particular are discussed, with a focus on statistical power and model-based theory testing.

\section{Keywords}

attachment; Strange Situation Procedure; candidate genes; sensitivity; $\mathrm{G} \times \mathrm{E}$

\section{Introduction}

There can be little doubt that in the last decade there has been intense and increasing interest about the role of candidate genetic markers in developmental adaptation. Indeed, such work has proliferated not only in substantive areas in which there is good reason to expect that the outcomes of interest are non-trivially correlated with genetic variation (e.g., studies of personality traits demonstrated in behavior-genetic research to be substantially heritable; Wacker, Mueller, Hennig, \& Stemmler, 2012) but also, somewhat paradoxically, in relation to phenotypes - such as infant attachment security - for which relevant monozygotic and dizygotic twin comparisons actually suggest minimal genetic influence (e.g., Fearon et al., 2006; Roisman \& Fraley, 2008). Despite such enthusiasm, there has recently been something of a backlash to candidate gene studies on the grounds that key findings, whether main-effect genetic associations or gene-environment interaction $(\mathrm{G} \times \mathrm{E})$ effects, have proven difficult to replicate (Charney \& English, 2012; Ioannidis, 2003; Munafò, Durrant, Lewis, \& Flint, 2009).

There are many trivial reasons why studies might produce null findings and thereby fail to replicate seminal findings, including the inadequate measurement of key constructs and low statistical power to detect non-trivial effects. Undoubtedly, variation in findings in the candidate-gene literature are at least partly attributable to the relatively small samples used in both initial studies and replication attempts, as well as to variation in the quality of the assessment of relevant variables. In particular, that reliability data specific to genotyping are rarely reported in candidate gene studies in the psychological literature represents a major problem for progress in this area. But so, too, is the fact that there are literally millions of possible genetic markers that could be examined in such studies, combined with what has been termed flexible "researcher degrees of freedom" (Simmons, Nelson, \& Simonsohn, 2011) that make it entirely within current convention for scholars to report statistically significant associations in underpowered studies while failing to report the effects of other genetic polymorphisms that generate null results.

The literature on the molecular genetics of infant attachment and disorganization in many respects represents a prototypic case study of the deficiencies of current practice in generating replicable results in this area. First, as already noted, relevant behavior-genetic evidence suggests that early attachment-related variation is a rare example of a psychological phenotype for which estimated additive genetic contributions are either small or nil (cf. Turkheimer, 2000). Second, most molecular-genetic studies in this area are clearly underpowered in relation to conventional wisdom (and now abundant evidence from large 
scale studies) that genetic main and interaction effects of individual polymorphisms (whether Single Nucleotide Polymorphisms [SNPs] or Variable Number Tandem Repeats [VNTRs]) are unlikely to account for more than $1 \%$ of the variation in psychological outcomes, and often considerably less (Turkheimer, 2011).

Third - and perhaps most importantly - the literature on infant attachment demonstrates how focus can shift rapidly and essentially ad infinitum from genetic marker to genetic marker in search of one (or more) that might be associated reliably with the outcomes of interest. For example, Lakatos and colleagues' (2000) seminal finding that carriers of the 7-repeat variant of the dopamine D4 receptor (DRD4) VNTR are at enhanced risk for disorganization in a modest-sized Hungarian sample quickly led to failures to replicate that result in larger samples (e.g., Bakermans-Kranenburg \& Van IJzendoorn, 2004), only to be followed up by suggestions that it was instead the serotonin transporter promoter polymorphism (5HTT VNTR) that might be involved in disorganization (Spangler, Johann, Ronai, \& Zimmermann, 2009) or perhaps security (Barry, Kochanska, \& Philibert, 2008). With 5HTT findings failing to replicate in four independent datasets (Luijk et al., 2011; Pauli-Pott, Friedl, Hinney, \& Bebebrand, 2009; Raby et al., 2012) and in light of mixed evidence from a fifth (Cicchetti, Rogosch, \& Toth, 2011), attention might now be turning toward oxytonergic SNPs. Indeed, Chen and associates (2011) recently presented evidence suggesting that associations between such SNPs and attachment security might be specific to non-White infants and only some (rs2254298) but not other (rs53576) oxytonergic markers.

Such nuanced findings may turn out to be generalizable truths. Alternatively, the proliferation of many of the results in the literature on the molecular-genetic correlates of infant attachment (and their subsequent failures to replicate) might be attributable more parsimoniously to the possibility that such findings are spurious (or substantially overestimated) effects that are the inevitable result of relatively small-sample research combined with the freedom to conduct multiple comparisons. In order to begin to address this possibility, we - together with our Dutch colleagues - recently reported analyses from the two largest studies of their kind - the NICHD Study of Early Child Care and Youth Development (SECCYD), a long-term longitudinal study of Americans born in 1991, and Generation R, a longitudinal study of a young Dutch cohort (combined $N$ of over 1000 infants). More specifically, we examined the degree to which almost all of the candidate genes discussed in the literature on the molecular genetics of infant attachment are associated either with attachment security or disorganization (Luijk et al., 2011). In short, we failed to replicate evidence from smaller-sample studies that a set of dopaminergic (DRD2 rs1800497, DRD4 VNTR, COMT rs4680), serotonergic (5HTT VNTR), and oxytonergic (OXTR rs53576, OXTR rs2254298) polymorphisms were significantly associated with infant attachment-related variation across the two datasets. Moreover, we did not observe consistent $\mathrm{G} \times \mathrm{E}$ evidence that early sensitive caregiving interacted with any of these polymorphisms in the prediction of either early attachment security or disorganization.

This report extends previous work by providing a set of empirical examples based on the NICHD SECCYD that further highlight the fragility of findings from molecular-genetic association studies based on small samples. These examples update and extend the results 
reported in Luijk et al. (2011) in three key ways. First, since Luijk et al. (2011) was published, molecular-genetic data from the SECCYD have been refined, reliability data gathered, and additional polymorphisms genotyped (most notably the DRD4 SNP rs1800955, which was featured in Lakatos and colleagues' [2002] early research on attachment-related disorganization). Using these updated data, we report here the individual associations and average effect of the full range of candidate markers examined to date in the literature on the putative genetic origins of infant attachment security and disorganization. In particular, we draw attention in this analysis to the fact that researchers working in this area have considerable flexibility in how to model their genetic data - and ultimately which models to report. Specifically, this paper presents additive models (i.e., number of "risk" variants, typically ranging from 0 to 2), dominance models ("risk" allele carrier versus not), and another binary model that compares infants homozygous versus heterozygous on the markers of interest. ${ }^{1}$ In addition, this paper revisits evidence in the SECCYD that the predictive significance of maternal sensitivity for attachment security and/or disorganization might be moderated by genotype using genetic dominance models, as in Luijk et al. (2011).

Second, Luijk et al. (2011) reported data based exclusively on the non-Hispanic/White subsample of the SECCYD in order to sidestep concerns related to ethnic stratification confounding. Current research reports associations between the candidate polymorphisms featured in this literature and attachment in the White and non-White sub-samples of the SECCYD. We do so particularly in light of the aforementioned report claiming that GG (in contrast to AG and AA) carriers of OXTR rs2254298 (but not OXTR rs53576) are at enhanced risk for infant attachment insecurity in non-White (but not White) samples (Chen et al., 2011).

Third, this paper attempts to replicate a recent finding by Raby et al. (2012) based on the Minnesota Longitudinal Study of Risk and Adaptation suggesting that, although molecular genetic "usual suspects" might not be implicated in security versus insecurity, the serotonin transporter gene (5HTT VNTR) contributes to variation in emotional distress during the Strange Situation. As in Raby et al. (2012), we operationally define distress during the Strange Situation using a classic distinction first suggested by Belsky and Rovine (1987), grouping relatively low distress secure babies $\left(\mathrm{B}_{1}, \mathrm{~B}_{2}\right)$ with avoidant $(\mathrm{A})$ infants and more distressed but still (categorically) secure babies $\left(\mathrm{B}_{3}, \mathrm{~B}_{4}\right)$ with resistant $(\mathrm{C})$ infants. Raby et al. (2012) reported that infants in the high distress group were more likely to be carriers of the short form of the serotonin transporter gene than were infants in the low distress group.

\footnotetext{
${ }^{1}$ To further complicate matters, genetic models can be guided by the alternative assumption that the "non-risk" variant of a given polymorphism is dominant (e.g., "recessive" models), in which case one might compare individuals homozygous for the risk variant with the combined group of those with one or two copies of the non-risk variant. We did not pursue such analyses here because all prior publications in this area have either assumed that the "risk" variant is dominant or reported additive genetic models. Nonetheless, the non-trivial number of possible genetic models one could examine - along with the fact that it is not always self-evident in advance which variant might be conceptualized as the one that increases the probability of a given outcome (i.e., often the rare variant but occasionally the more common one known as the "wildtype") - clearly increases risk for Type I errors.
} 


\section{Methods}

\section{Participants}

Analyses for this report are based on the 674 participants from the NICHD SECCYD (sampling for the full sample described in detail in NICHD Early Child Care Research Network [ECCRN], 2005) for whom buccal cheek cells were acquired when participants were 15 years old and who had previously participated as infants with their mothers in the Strange Situation Procedure (SSP) at age 15 months. (A total of 711 participants provided DNA samples at age 15 years, although 26 participants lacked Strange Situation data and another 11 DNA samples acquired did not produce valid genotypic data for any of the candidate genes examined in this report and, thus, relevant cases were dropped from examination.) As in Chen et al. (2011), we sub-divided the SECCYD sample further into non-Hispanic/White participants $(n=530)$ and non-White participants $(n=144$; for this analysis, we included a small sub-set of White/Hispanic infants in the non-White group. Results were unchanged when these participants were excluded). Sample sizes for analyses varied further as a function of the availability of genotypic data for each polymorphism (see Table 1).

\section{Measures}

Maternal sensitivity-Mother-child interactions were videotaped during 15-min semistructured tasks at 6 and 15 months. At both 6 and 15 months, an a priori maternal sensitivity composite was constructed by summing ratings for sensitivity to non-distress, positive regard, and intrusiveness (reversed). Internal consistencies of these a priori composites were .75 for the 6-month composite, and .70 for the 15-month composite; intercoder reliabilities on the scales were $>.80$ (NICHD ECCRN, 1998). Observations of maternal sensitivity from the two time points $(r=.39$ [1214], $p<.01$ in the full SECCYD sample) were averaged to form a composite for the current analysis.

Attachment security, disorganization, and distress-Attachment measures were derived from the SSP (Ainsworth, Blehar, Waters, \& Wall, 1978) administered to motherinfant dyads when the infant was about 15 months old. The SSP is a well-validated procedure to measure attachment quality, consisting of seven 3-min episodes designed to evoke mild stress to trigger attachment behavior.

From the SSP we derived a continuous Attachment Security Scale score (Richters, Waters, \& Vaughn, 1988), which has been used widely (e.g., Kochanska, Aksan, Knaack, \& Rhines, 2004; Luijk et al., 2011) in place of the more standard attachment categories because predictive validity can be attenuated using categorical assessments of an individual difference that has a continuous latent distribution (Fraley \& Spieker, 2003). Van IJzendoorn and Kroonenberg (1990) adapted and validated the algorithm for use with SSP interactive scales (proximity seeking, contact maintenance, resistance, and avoidance) during the two reunion episodes in the SSP (episodes 5 and 8 ) without scores for crying. The algorithm yields a continuous score for attachment security (i.e., security $=0.13 *$ proximity seeking [episode 5] $-0.41 *$ contact maintenance [episode 5] $-0.17 *$ resistance [episode 5] $-0.25 *$ avoidance [episode 5] $+0.19 *$ proximity seeking [episode 8 ] $+0.54 *$ contact 
maintenance [episode 8] $-1.44 *$ resistance [episode 8] $-0.9 *$ avoidance [episode 8] +4.5 ) that is strongly associated with the secure vs. insecure attachment classifications (with higher security scores indicating a more secure attachment relationship). Continuous scores for disorganization were derived from the standard 9-point coding scale for disorganization (Main \& Solomon, 1990), with higher scores indicating more disorganized behavior. Intercoder reliability estimates (intraclass correlation coefficients [ICC]) for the continuous attachment security and disorganization scales were .92 and .84 , respectively (full $N=$ 1191).

Infants also were assigned to high or low distress groups, based on Belsky and Rovine (1987), who derived this measure from standard attachment categories and validated it against reports of negative emotionality earlier in life. Specifically, infants coded as $\mathrm{B}_{1}, \mathrm{~B}_{2}$, or A were assigned to the low distress group and infants coded as $\mathrm{B}_{3}, \mathrm{~B}_{4}$, and $\mathrm{C}$ were assigned to the high distress group. Infants classified as disorganized or unclassifiable were excluded from this particular analysis.

\section{Genetic data reduction}

Overview-Genotyping was performed for markers in the dopaminergic (DRD2 rs1800497, DRD4 48 bp VNTR, DRD4 rs1800495, COMT rs4680), serotonergic (5HTT VNTR), and the oxytonergic (OXTR rs53576, OXTR rs2254298) systems. See Table 1 for the risk alleles. (Frequency distributions for the SNPs in this sub-sample did not depart significantly from Hardy-Weinberg equilibrium, with the exception of DRD4 rs1800495, $\chi^{2}$ $=32.2, p<.001$.)

Extraction-Extraction for all polymorphisms was based on adaptations to Freeman et al. (2003). Specifically, buccal mucosa cells were collected with cotton swabs by the participant. The swabs were placed in $15 \mathrm{ml}$ centrifuge tubes containing $2.5 \mathrm{ml}$ of lysis buffer. The tubes were incubated in a water bath at $65^{\circ} \mathrm{C}$ for $2 \mathrm{hr}$ to activate the proteinase $\mathrm{K}$. After incubation, the tubes were centrifuged at $300 \mathrm{~g}$ for $4 \mathrm{~min}$ and the supernatant added to $4 \mathrm{ml}$ of isopropanol. Tubes were centrifuged again for $30 \mathrm{~min}$. The supernatant was poured off, the pellet dried, and $1 \mathrm{ml}$ of lysis buffer without proteinase $\mathrm{K}$ was added. Pellets were re-suspended by shaking overnight. The liquid was transferred to a $1.5 \mathrm{ml}$ microfuge tube and $200 \mu \mathrm{l}$ of an organic deproteinization reagent (ODPR) were added to each tube. The tubes were capped and shaken vigorously by hand. The denatured debris and remaining organic mix were then centrifuged at $5000 \mathrm{~g}$ for $10 \mathrm{~min}$. Supernatant from the tube was transferred to a fresh $1.5 \mathrm{ml}$ tube and $800 \mu \mathrm{l}$ of isopropanol was added and mixed gently for approximately $1 \mathrm{~min}$. The DNA was collected by centrifugation at $5000 \mathrm{~g}$ for $10 \mathrm{~min}$. The pellets were dried and washed with $1 \mathrm{ml}$ ethanol $70 \%(\mathrm{v} / \mathrm{v})$ by centrifugation at $5000 \mathrm{~g}$ for $10 \mathrm{~min}$. The ethanol wash was discarded, the tubes were inverted, and the pellets were dried for $60 \mathrm{~min}$. The DNA was re-suspended in $250 \mu \mathrm{l}$ of Tris EDTA (TE) buffer (10 mM Tris$\mathrm{HCl}, 1 \mathrm{mM}$ EDTA, $\mathrm{pH} 8.0$ ) by rotation in an incubator at $37^{\circ} \mathrm{C}$. The DNA was quantified by measuring the absorbance at $260 \mathrm{~nm}$ using a Nanodrop spectrophotometer. Samples were aliquoted into storage vials and placed in a $-80^{\circ} \mathrm{C}$ freezer. 
DRD2 rs1800497 SNP-In order to genotype DRD2, Taqman SNP Genotyping Assays were performed using an Allelic Discrimination Assay (Applied Biosystems, Foster City, CA) protocol. Forty nanograms of DNA were combined in a volume of $5 \mu \mathrm{l}$ with $2 \mathrm{X}$ Universal PCR Mix (Applied Biosystems) and 1/20 the volume of the Taqman SNP assay in a 384 well plate. A Pre-Read was performed and then PCR as follows: a 10 min hold at $95^{\circ} \mathrm{C}$, followed by $40-45$ cycles of $15 \mathrm{sec}$ at $92^{\circ} \mathrm{C}$, and then $1 \mathrm{~min}$ at $60^{\circ} \mathrm{C}$ in a $7900 \mathrm{HT}$ PCR System. After amplification, a Post-Read was performed to analyze. Automatic and manual calls were made. Reliability genotyping for this SNP was conducted on an Open Array (see description under DRD4 rs1800495 below).

DRD4 VNTR-The assay for genotyping the DRD4 VNTR was based on methods developed by Sander et al. (1997) and modified by Anchordoquy, McGeary, Liu, Krauter, and Smolen (2003). The Genomics Core Facility at Pennsylvania State University (PSU) modified it further as the following: $1 \times$ Taq Gold Buffer, $2.25 \mathrm{mM}$ final concentration of $\mathrm{MgCl} 2,10 \%$ DMSO, $0.2 \mathrm{mM}$ dNTPs, $0.1 \mathrm{mM}$ deazo GTP, $0.75 \mathrm{uM}$ primers, $40 \mathrm{ng}$ of DNA, and $1 \mathrm{U}$ of Taq Gold (Applied Biosystems, Foster City CA) in a volume of $12 \mu \mathrm{l}$. The primer sequences are: 5' -6 -FAM-GCGACTACGTGGTCTACTCG- $3^{\prime}$ and reverse, $5^{\prime}$ AGGACCCTCATGGCCTTG- $3^{\prime}$. The amplification procedure was as described by Anchordoquy et al. (2003). One microliter was removed and placed in a 96 well plate and 10 $\mu \mathrm{l}$ of formamide containing LIZ-500 standard (Applied Biosystems, Foster City, CA). The plate was run using a Fragment Analysis protocol in the 3730XL DNA Analyzer (Applied Biosystems, Foster City, CA). Fragments were analyzed using Genemapper software (Applied Biosystems, Foster City, CA) with PCR products of (in bp): 379, 427, 475 (43), $523,571,619(73), 667,715,763$, and 811. Reliability genotyping was also conducted as described immediately above.

DRD4 rs1800495 SNP-This DRD4 SNP (including relevant reliability genotyping) was genotyped on an Open Array. Specifically, SNPs were determined using the OpenArray ()$^{\circ}$ Real-Time PCR System (Applied Biosystems, Foster City, CA) as in User Guides PN \#4458837 Rev. A and PN \#4458840A. Briefly, genomic DNA was added to 96 well plates at the recommended concentration and then transferred to 384 well plates along with the TaqMan® OpenArray® Gene Expression Master Mix. The 384 well plates and OpenArray@ slides were placed in an OpenArray@ AutoLoader (Applied Biosystems, Foster City, CA) that automatically transferred the solution from the plate to the slide. The slide was placed in the Genotyping Case and then in an Applied Biosystems GeneAmp( PCR System 9700 thermal cycler (Applied Biosystems, Foster City, CA). The OpenArray® Run Method was $93^{\circ} \mathrm{C}$ for $10: 00 \mathrm{~min}$ followed by 60 cycles of $95^{\circ} \mathrm{C}$ for $0: 45 \mathrm{~min}, 94^{\circ} \mathrm{C}$ for 0:13 min, and $53^{\circ} \mathrm{C}$ for $2: 14 \mathrm{~min}$. A final step of $25^{\circ} \mathrm{C}$ for 2:00 min was run before setting the module to $4^{\circ} \mathrm{C}$ forever. A spreadsheet file composed of sample names was prepared and uploaded into the OpenArray@ Image software along with the serial number of the slide. After cycling, the slide was placed in the OpenArray $\odot$ NT Imager and imaged. OpenArray $\odot$ SNP Genotyping Analysis Software v1.0.3 was used to analyze the data.

COMT rs4680 SNP—For COMT, Taqman SNP Genotyping Assays were performed using an Allelic Discrimination Assay (Applied Biosystems, Foster City, CA) protocol. Forty 
nanograms of DNA were combined in a volume of $5 \mu \mathrm{l}$ with $2 \mathrm{X}$ Universal PCR Mix (Applied Biosystems) and 1/20 the volume of the Taqman SNP assay in a 384 well plate. A Pre-Read was performed and then PCR as follows: a 10 min hold at $95^{\circ} \mathrm{C}$, followed by $40-$ 45 cycles of $15 \mathrm{sec}$ at $92^{\circ} \mathrm{C}$, and then $1 \mathrm{~min}$ at $60^{\circ} \mathrm{C}$ in a $7900 \mathrm{HT}$ PCR System. After amplification, a Post-Read was performed to analyze. Automatic and manual calls were made. Reliability genotyping was conducted on an Open Array (see description under DRD4 rs1800495 above).

5HTT VNTR - The assay for 5HTT was a modification of the method of Lesch et al. (1996) and Anchordoquy et al. (2003). The Genomics Core Facility at PSU modified it further as the following: $1 \times$ Taq Gold Buffer, $1.8 \mathrm{mM}$ final concentration of $\mathrm{MgCl} 2,10 \% \mathrm{DMSO}, 0.2$ $\mathrm{mM}$ dNTPs, $0.1 \mathrm{mM}$ deazo GTP, $0.6 \mu \mathrm{M}$ primers, $40 \mathrm{ng}$ of DNA, and $1 \mathrm{U}$ of Taq Gold (Applied Biosystems, Foster City CA) in a volume of $15 \mu \mathrm{l}$. The primer sequences were: forward, 5' -VIC- GGCGTTGCCGCTCTGAATGC-3' and reverse, $5^{\prime}$ -

GAGGGACTGAGCTGGACAACCAC-3'. The same amplification protocol as used for DRD4 was used for 5HTLL. One microliter was removed and placed in a 96 well plate and 10 microliters of formamide containing LIZ-500 standard (Applied Biosystems, Foster City, CA). The plate was run using a Fragment Analysis protocol in the 3730XL DNA Analyzer (Applied Biosystems, Foster City, CA). Fragments were analyzed using Genemapper software (Applied Biosystems, Foster City, CA) with PCR products of 484 or $528 \mathrm{bp}$. Reliability genotyping was also conducted as described immediately above.

OXTR rs53576 SNP_For OXTR rs53576, Taqman SNP Genotyping Assays were performed using an Allelic Discrimination Assay (Applied Biosystems, Foster City, CA) protocol. Forty nanograms of DNA were combined in a volume of $5 \mu$ with $2 \mathrm{X}$ Universal PCR Mix (Applied Biosystems) and 1/20 the volume of the Taqman SNP assay in a 384 well plate. A Pre-Read was performed and then PCR as follows: a 10 min hold at $95^{\circ} \mathrm{C}$, followed by $40-45$ cycles of $15 \mathrm{sec}$ at $92^{\circ} \mathrm{C}$, and then $1 \mathrm{~min}$ at $60^{\circ} \mathrm{C}$ in a $7900 \mathrm{HT}$ PCR System. After amplification, a Post-Read was performed to analyze. Automatic and manual calls were made. Reliability genotyping was also conducted as described immediately above.

OXTR rs2254298 SNP_Finally, for OXTR rs2254298 Taqman SNP Genotyping Assays were performed using an Allelic Discrimination Assay (Applied Biosystems, Foster City, CA) protocol. Forty nanograms of DNA were combined in a volume of $5 \mu$ with $2 \mathrm{X}$ Universal PCR Mix (Applied Biosystems) and 1/20 the volume of the Taqman SNP assay in a 384 well plate. A Pre-Read was performed and then PCR as follows: a 10 min hold at $95^{\circ} \mathrm{C}$, followed by $40-45$ cycles of $15 \mathrm{sec}$ at $92^{\circ} \mathrm{C}$, and then $1 \mathrm{~min}$ at $60^{\circ} \mathrm{C}$ in a $7900 \mathrm{HT}$ PCR System. After amplification, a Post-Read was performed to analyze. Automatic and manual calls were made. Reliability genotyping was also conducted as described immediately above.

Reliability genotyping-For SNPs in the $N=674$ sub-sample, reliability was ascertained by genotyping $n=69(\sim 10 \%)$ samples twice, with discrepancies resolved via a third genotyping. For DRD2 rs1800497, COMT rs4680, and OXTR rs2254298, 100\% of 
reliability cases were in agreement ( 1-2\% of samples could not be genotyped for each of these SNPs in the $N=674$ sub-sample). For DRD4 rs1800495, 15\% of samples could not be genotyped in this sub-sample and $\kappa_{\text {additive }}=0.93,96 \%$ agreement; $\kappa_{\text {dominance }}=0.95,99 \%$ agreement; and $\kappa_{\text {homozygous vs. not }}=0.90,96 \%$ agreement (all $p \mathrm{~s}<.001$; note that, because DRD4 rs1800495 was assayed during a second round of genotyping, there was an additional set of cases in the $N=674$ sub-sample that were by that time unusable and for which genotyping on this SNP was not attempted; $n=48,7.1 \%$ ). Finally, for OXTR rs53576, 3.6\% of samples could not be genotyped in this sub-sample and $\kappa_{\text {add }}=0.83,90 \%$ agreement; $\kappa_{\mathrm{dom}}=0.86,93 \%$ agreement; and $\kappa_{\text {hom }}=0.79,90 \%$ agreement (all $p$ s $\left.<.001\right)$.

Given the greater challenges associated with genotyping VNTRs (particularly after a significant delay from collection, as was the case in this study), to the extent possible, we genotyped each sample for the two VNTRs twice. A third genotyping was conducted to resolve discrepancies. However, we defaulted to the original genotype if a sample could not be genotyped a second time or if we were unable to identify a single genotype for a given sample (in some cases samples were used up or degraded such that calls on a given VNTR were no longer possible). For DRD4, 4.6\% of cases in the $N=674$ sub-sample could not be genotyped and $\kappa_{\mathrm{add}}=0.51,80 \%$ agreement; $\kappa_{\mathrm{dom}}=0.52,81 \%$ agreement; and $\kappa_{\mathrm{hom}}=0.50$, $82 \%$ agreement (all $p$ s <.001). For 5HTT, 3.3\% of cases in the $N=674$ sub-sample could not be genotyped and $\kappa_{\text {add }}=0.69,80 \%$ agreement; $\kappa_{\text {dom }}=0.74,89 \%$ agreement; and $\kappa_{\text {hom }}$ $=0.64,82 \%$ agreement (all $p$ s <.001). Note that a coding error in Luijk et al. (2011) rendered the distribution of 5HTT genotypes reported there (based on the SECCYD sample only) incorrect. The distribution of the 5HTT VNTR genotypes has been updated and corrected for presentation here in Table 1.

\section{Results}

\section{Distribution of attachment scores and correlations with sensitivity}

Mean security scale scores were $1.21(S D=3.17)$ for (non-Hispanic) White infants and 1.37 $(S D=2.74)$ for non-White infants; mean disorganization scores were $2.39(S D=2.01)$ for White infants and $2.58(S D=2.19)$ for non-White infants. Table 1 presents means and standard deviations of security and disorganization scores by genotype for White and nonWhite infants separately. The correlation between sensitivity (mean at 6 and 15 months) and security was $.09, p<.05$ for White infants and $.12, p=.15$ for non-White babies in this subsample. The correlation between sensitivity and disorganization was .04, $p=.31$ for White infants and $-.12, p=.15$ for non-White babies in this subsample.

\section{Main effect candidate gene associations}

Additive genetic models-Correlations $\left(r_{\text {add }}\right)$ and exact $p$-values $\left(p_{\text {add }}\right)$ based on additive genetic models (number of "risk" variants) are reported in Table 2 by ethnicity for security (top panel) and disorganization (bottom panel). Consistent with Luijk et al. (2011), for White infants none of these associations was statistically significant. ${ }^{2}$ For non-White participants, one out of 14 analyses (seven candidate genes * two dependent measures) produced a statistically significant result. Specifically, individuals carrying more 7+ repeats of the DRD4 VNTR were more likely to be disorganized (again, only in the non-White sub- 
sample). ${ }^{3}$ The average effect of the polymorphisms for the White and non-White samples on security was a mean correlation of .03 and .01, respectively (counterintuitive mean effects because the risk alleles were associated with trivially higher levels of security, on average). The average effect of the polymorphisms for the White and non-White samples on disorganization was a mean correlation of .03 and -.01, respectively.

Genetic dominance models-Table 2 also reports genetic dominance analyses (i.e., risk carrier versus not). Once again, most of the results were null, although for White infants we now identified a small $\left(r_{\text {dom }}=.08\right)$ but significant, not previously reported, effect of COMT for disorganization. For non-White infants only, we observed once again a significant effect of carrying the DRD4 7+ repeat for disorganization (see Note 3). That said, the average effect of the polymorphisms on security was .02 and approximately .00 for White and nonWhite participants, respectively. Similarly, the average effect of the polymorphisms on disorganization was .04 and .01 for White and non-White participants, respectively.

Heterozygous vs. homozygous genetic association models-Because we previously reported in Luijk et al. (2011) that COMT rs4680 heterozygotes were significantly (though modestly) more likely to be disorganized in both the SECCYD and the Generation R studies, we examined the predictive significance $\left(r_{\text {hom }}\right)$ of being homozygous on all polymorphisms for security and disorganization. For White participants, as we reported in Luijk et al. (2011), COMT heterozygotes were significantly (though again modestly) more likely to be disorganized $\left(r_{\text {hom }}=-.09, p_{\text {hom }}<.05\right)$. Interestingly - and further complicating a straightforward interpretation of findings reported above that DRD4 $7+$ repeat carriers were at increased risk for disorganization among non-Whites - our analysis of homozygosity versus heterozygosity revealed that non-White infants with zero or two 7+ repeats had, as a group, significantly lower disorganization scores than did those with a single 7+ DRD4 repeat (also see Note 3). Non-White (but not White) infants homozygous for the DRD4 SNP rs1800495 also had significantly higher disorganized scores. Nonetheless, once again, the average effect of being homozygous for the candidate genes was approximately zero for security and disorganization in both sub-samples.

\footnotetext{
${ }^{2}$ Throughout the manuscript we refer to results as statistically significant when $p<.05$ without correction for multiple testing. There are a number of ways that analysts can attempt to correct for multiple comparisons in order to minimize the false discovery (i.e., Type I error) rate. The most conservative of these - the Bonferroni correction whereby nominal alpha is divided by the number of analyses conducted - resulted in no statistically significant results post-correction.

${ }^{3}$ Another reason that care should be taken in interpreting the few ambiguous DRD4 VNTR effects identified in the non-White subsample in the SECCYD is that, in order to maintain continuity with Luijk et al. (2011), we grouped low base rate repeat carriers in excess of 7-repeats ("long-repeats"; e.g., 8-, 9-, and 10-repeat carriers) with 7 repeat cases as "risk" allele carriers. However, not all investigators group carriers of repeats above 7 with $7 \mathrm{~s}$ given that the functional equivalence of low base rate variants of VNTRs like DRD4 relative to more common variants is often in dispute or simply unknown. Indeed, in their seminal analysis, Lakatos et al. (2002) combined all low base rate repeat carriers on the DRD4 VNTR (i.e., all "short" repeats such as 3-, 5-, and 6-repeats as well as "long" repeats such as 8-, 9-, and 10-repeats) with the most common repeat variants (2- and 4-repeats) and contrasted that group with 7-repeat carriers (i.e., 7- versus 7+). When we focused on this slightly different operationalization of risk status, no significant associations emerged between the DRD4 48 bp VNTR (using additive, dominance, or homozygous vs. heterozygous genetic models) and attachment security or disorganization in either ethnic group (i.e., White/non-Hispanic or non-White), suggesting once again that statistically significant findings in this literature can be highly fragile, in this case as a function of subtle, arguably arbitrary coding choices (see Charney \& English, 2012, for an excellent discussion of this issue in relation to the monoamine oxidase-A [MAOA] VNTR).
} 


\section{Maternal sensitivity $\times$ genotype interactions}

In the interest of space, as in Luijk et al. (2011) we focused on dominance models to examine interactions between the candidate genes and sensitivity in the prediction of security and disorganization (maternal sensitivity was centered on the grand mean for $N=$ 674 for all analyses; see Tables 3 and 4). In the prediction of security, no significant $\mathrm{G} \times \mathrm{E}$ interactions were found for White or non-White infants. (In unreported analyses we also examined COMT homozygous versus heterozygous $\times$ sensitivity as in Luijk et al. [2011]. This, too, produced a null result for the interaction term.) In the prediction of disorganization, only one significant interaction effect emerged (sensitivity $\times$ 5HTT VNTR), for White infants only. However, probing of this interaction revealed a somewhat counterintuitive, contrastive interaction that was inconsistent with superficially similar results presented in Spangler et al. (2009): the association between sensitivity and disorganization was marginally negative $(r=-.14, p=.09)$ for $1 / 1$ carriers and counterintuitively positive, albeit only marginally so $(r=.10, p=.07)$, for s carriers ( $\mathrm{s} / 1$ and $\mathrm{s} / \mathrm{s})$. (In unreported analyses we also examined the interaction between the DRD4 VNTR and DRD4 rs1800495 in the prediction of disorganization as in Lakatos et al. [2002]. This produced non-significant interaction effects in both sub-samples, although the interaction effect for non-White participants was marginally significant.)

\section{Revisiting Raby et al. (2012)}

Finally, this paper examined the association between being grouped as a low $\left(A, B_{1}\right.$, or $\left.B_{2}\right)$ versus a high $\left(\mathrm{B}_{3}, \mathrm{~B}_{4}\right.$, or $\left.\mathrm{C}\right)$ distress infant in the Strange Situation Procedure and carrying short forms of the serotonin transporter gene, using a genetic dominance model (short carrier vs. homozygous long). In contrast to Raby et al.'s finding, in the White sub-sample of the SECCYD we found that the high distress group $(M=0.65, S D=0.48, n=199)$ was significantly less likely than the low distress group $(M=0.75, S D=0.43, n=232)$ to be carriers of the short form of the serotonin transporter gene (equivalent to an $r[431]=-.12, p$ $<.05)$. In the non-White sub-sample, the relevant effect trended in the opposite direction $(r[104]=.18, p=.06$; low distress: $M=0.59, S D=0.50, n=58$; high distress: $M=0.76, S D$ $=0.43, n=46$ high distress). ${ }^{4}$ (As a check on these results, we examined whether the 5HTT VNTR was associated with a continuous assessment of distress - mean distress observed during episodes 4, 6, and 7 of the Strange Situation Procedure. The pattern of results among White and non-White infants was essentially identical to the results described using the Belsky and Rovine [1987] groups.)

\section{Discussion}

Updating and extending findings from the NICHD SECCYD presented in Luijk et al. (2011), this report reveals that the average effect of all polymorphisms examined to date in the literature on the molecular genetic correlates of infant attachment on infant attachment security and disorganization hovers around zero for White and non-White infants in this sample. Similarly, this paper found little consistent evidence to support the finding of Raby

\footnotetext{
${ }^{4}$ The pattern of findings was identical when we applied an additive genetic model (i.e., number of short forms of the 5HTT VNTR from 0-2) that was more consistent with the approach taken in Raby et al. (2012).
} 
et al. (2012) that high-distress infants were more likely to be carriers of the short form of the serotonin transporter gene. In fact, we found a small, statistically significant effect in the opposite direction for White infants.

Current research believes that these analyses advance discussion on the role of genetic variation in relation to infant attachment in two ways. First, we have updated Luijk et al. (2011) and demonstrated in the SECCYD trivial effects of the SNPs and VNTRs thus far examined as candidate genetic correlates of security and disorganization. Second, and more generally, we view this analysis as something of a cautionary tale - without proper attention to statistical power, research on the genetic correlates of attachment-related variation (and indeed of developmental adaptation more generally) is not likely to produce replicable results.

As noted in the Introduction, our inability to replicate results in this literature (along with similar results from the comparably large-sample Generation R study; seeLuijk et al., 2011) is predictable from the underpowered nature of almost all studies in this area. To be clear, it is entirely reasonable for developmental psychologists to view studies of, say, 150 participants as providing ample statistical power to detect the kinds of "small" to "moderate" (and larger) bivariate associations that emerge routinely in studies examining the predictive significance of constructs such as maternal sensitivity (see, e.g., Fraley, Roisman, \& Haltigan, 2012). Indeed, analysts have $80 \%$ power to detect a "small" to "moderate" sized $r$ $=.20$ or larger with such samples (assuming a directional prediction and the use of onetailed test; $N=193$ is required in the two-tailed case). In contrast, however, reliably detecting the kinds of associations that are anticipated for specific genetic markers (i.e., effects explaining $1 \%$ of the variance or less) requires much larger samples.

For this reason, if research in this area is to be pursued using a candidate gene approach, current practice in our field must accommodate these design-related issues. One approach if there is agreement that trivial associations in this area (e.g., $r<.10)$ are of little theoretical interest - is for studies to include at least enough participants to have adequate power to determine whether relevant genetic effects make that cut-off (e.g., $80 \%$ power to reliably differentiate an $r=.10$ or larger from zero requires 617 participants, assuming a directional prediction). ${ }^{5}$ To be clear, the alternative approach now widespread in the field - assuming that statistically significant results obtained in underpowered studies will prove replicable reveals a misunderstanding about the methodological protection offered by $p$-values in the context of multiple comparisons, as the results of this analysis illustrate (see also Fraley \& Marks, 2007).

In the interest of full disclosure, by the standards described above, the non-White analyses reported here are clearly underpowered (although less so than in the non-White sample studied by Chen et al., 2011). Indeed, it is for this reason that these analyses are likely less informative about the genetic correlates of infant attachment-related variation among nonWhite infants specifically and instead are instructive more generally about how significant,

\footnotetext{
5 In the absence of a directional prediction (i.e., a common scenario in molecular genetic research where the "risk" or "plasticity" variant cannot be articulated unambiguously in advance and for which a two-tailed alpha threshold is thus required), $80 \%$ power to detect a true effect of $r= \pm .10$ or larger requires a minimal $N$ of 782 .
} 
but ultimately non-replicable, genetic findings can emerge in the context of relatively small $N$ studies (but see Note 3 for additional caution regarding the few significant results we report for the DRD4 VNTR in the non-White sub-sample). Nor should our analysis be taken as an endorsement of Chen et al.'s (2011) approach of studying the molecular genetic correlates of attachment within a mixed ethnicity (e.g., non-White) sample without proper controls for ethnic stratification, as significant results obtained in such samples can be confounded with ethnicity.

As we elaborate below, the use of adequately powered studies in this area would represent a major improvement in study design. However, in this context it is important to emphasize that, even if this advice were implemented consistently moving forward, a deeper, more pernicious, and fundamentally structural issue would nonetheless remain due to the nature of (nil) Null Hypothesis Significant Testing (NHST). Specifically, given the multi-determined nature of development, there is actually very little reason to assume that the association between any particular SNP or VNTR and any particular developmental phenotype is precisely zero. What this means is that, with enough $N$, all genetic associations - however trivial in magnitude - will be detected as statistically significant (i.e., on the assumption that the null hypothesis that $r=.00$ is true, the value obtained should be rarely observed). This observation is, of course, neither new nor specific to molecular genetics research (Meehl, 1967).

As is (or should be) well appreciated, in studies in which directional hypotheses can be articulated a priori (i.e., sensitive caregiving would be expected to be associated with higher levels of social competence), as statistical power approaches $100 \%$ NHST will yield support for the hypothesis $50 \%$ of time, as all that need be obtained is a correlation in the direction predicted by the theory, even if the magnitude of the relevant association is trivial. This is very bad for scientific progress that hinges on theory testing. But worse yet is that in many molecular genetic association studies this general problem is compounded when (as is often the case) the "risk" variant cannot be unambiguously identified in advance. In this case (i.e., lacking a directional prediction), with enough statistical power, every analysis conducted will yield support for the hypothesis that essentially any measured genetic variant plays some role in the development of the focal phenotype.

As is the case with other areas of psychology that have been severely criticized for overuse of NHST, a potential way forward is the further development of theoretical frameworks that generate riskier hypotheses, using a falsificationist philosophy of science under which larger samples represent a greater risk of refutation for the proposed theory. Unfortunately, much work remains to be done in this area as well. For example, hypotheses that predict associations between particular genetic markers and behavioral phenotypes do not always posit clear and compelling biological mechanisms by which those relations are expected to manifest. While this may be no worse than the (lack of) specificity of prediction in many other areas of psychology, the extensive potential for multiple comparisons due to proliferation of "usual suspect" genetic markers makes the issue especially pernicious for researchers interested in genetic links to behavior. As such, studies that directly measure biological mediators of gene-behavior associations are especially valuable. 
Our purpose is not to prescribe a narrow, lock-step approach to psychological theorizing. At the same time, however, the burden should be on users of directional predictions to demonstrate convincingly prior to publication why knowledge of a reliable nonzero association in the population, which could be of any magnitude, represents a genuine theoretical advance. It is difficult to see how the dangers of capitalizing on chance fluctuations that we have demonstrated above can be overcome when staying solely within this framework. Notably, developmentalists have more recently proposed theoreticallygrounded frameworks for ways in which genetic and other biological characteristics might interact with relevant environmental experience (Belsky \& Pluess, 2009). However, like all scientific theories, these must still grapple with the challenges of making specific predictions that generate clear and compelling tests of refutation.

Model-based comparisons are likely a crucial part of the solution here. Tests of competing statistical models (usually path analytic or structural equation models that include standard assumptions of linearity, but other models are possible) are becoming more common in the psychological literature, but more work needs to be done on mathematical models developed specifically for a given substantive area (Rodgers, 2010) and then tested for their ability to rule out wide ranges of alternative data points while ruling in a narrower set of observations (Roberts \& Pashler, 2000). It is important to note that in comparison to many other areas of psychological science, behavior geneticists were early to recognize the utility of structural equation models that partitioned phenotypic variation into additive genetic, shared environmental, and nonshared environmental components, with various extensions (Muthén, Asparouhov, \& Rebello, 2006; Neale \& Cardon, 1992; Rijsdijk \& Sham, 2002). However, much of recent molecular genetic research has, unfortunately in our view, moved away from model-based theory testing.

All of this said, it is not necessarily problematic that all genetic associations will be detected as statistically significant given enough $N$ if one's goal is merely to catalogue with a high degree of precision the size of the effect of interest, whether small or large in magnitude. Indeed, perhaps lost in our discussion so far is that the major contribution of large sample studies is that, all other things being equal, they provide much more precise estimates of the magnitude of relevant effects than do smaller sample studies. It is for this reason the work in this area would be greatly improved by simply taking two modest, common-sense steps:

Attend to statistical power (Cohen, 1992). Samples much smaller than 600 or 700 children are not sufficient for detecting the kinds of small main effects (and likely smaller $\mathrm{G} \times \mathrm{E}$ effects) expected in this domain. Rather than celebrating unexpectedly large molecular-genetic associations that obtain in underpowered studies, we would be better advised to regard such findings with a healthy dose of skepticism prior to replication in adequately powered samples.

Report all analyses conducted (Simmons et al., 2011). As we hope our empirical examples have illustrated clearly, there are many ways to combine and recombine molecular-genetic data, and multiple comparisons in turn greatly increase the likelihood of reporting something that isn't so (i.e., committing a Type I error). Even if a study that generated a focal effect is adequately powered, scholars must have good information about both: (a) how many analyses were run to achieve the result and (b) how fragile or 
robust a given finding is to arbitrary coding choices. Even better would be to replicate the result in question, a check that optimally can (and perhaps should) be built into research designs in advance of data collection (Moonesinghe, Khoury, \& Janssens, 2007; Uncles \& Kwok, 2012).

\section{Caveats and limitations}

Given that this paper was designed as a cautionary tale, it seems critical that we place in proper context the limitations of the empirical examples we presented. Most crucial in this regard, it has been argued that one of the reasons that it has been difficult to replicate results in this area involves the inadequate measurement of key constructs. The seminal finding that the predictive significance of stressful life events (SLEs) for depressive symptoms is moderated by the presence of the short form of the serotonin transporter polymorphism (Caspi, Sugden, \& Moffitt, 2003) makes for an illustrative example. Rutter, Thapar, and Pickles (2009), among others, claimed that one reason the Caspi et al. (2003) finding has gone on to receive ambiguous meta-analytic support (e.g., Risch, Herrell, \& Lehner, 2009) is because studies that have failed to find this effect inadequately measured stressful life events, depression, or both. Similarly, it has been claimed also that the 5HTT VNTR $\times$ SLE interaction effect is likely to be stronger when the 5HTT VNTR is recoded by taking into account whether individuals are A versus G carriers on the 5HTT rs25531 SNP in the long allele of the 5HTT VNTR (e.g., Zalsman et al., 2006) because of some evidence that the presence of the $G$ allele $\left[l_{G}\right]$ reduces gene expression to a level similar to that of the short allele (Hu et al., 2006). Both of these issues are relevant to properly weighing the results of our empirical examples.

In light of these critiques of prior replication failures in the molecular-genetic literature, we should note that, in the SECCYD, the observed reliability of the VNTRs we studied (i.e., 5HTT and DRD4) was somewhat weaker than for the SNPs, leading to more (albeit substantively trivial) divergence between this and the Luijk et al. (2011) report in the precise results obtained in the White sub-sample in relation to the VNTRs as compared with the SNPs examined. As we noted at the outset, lower than ideal reliability can result in failures to replicate earlier results that are probably more properly construed as Type II errors. In the current work, however, we would note several pertinent observations. First, the reliability estimates of the VNTR genotyping in the SECCYD were at levels in line with the standards against which psychological constructs are routinely judged. Second, it is not possible to know whether the genotyping of the VNTRs was any more or less reliable than in other publications in this literature because none of those papers, to our knowledge, report such information. Indeed, we were not able to find a single example of the systematic reporting of reliability of genotyping in the literature of the molecular genetics of infant attachment, although at least two papers (Lakatos et al., 2000; Pauli-Pott et al., 2009) did note that there were some test-retest genotyping discrepancies that needed to be resolved. Third, as mentioned in the Methods section, we sought to "harmonize" all genotypic discrepancies by conducting additional genotyping. Fourth, we would remind the reader that the associations reported in this paper were comparable in magnitude to those identified in the similarly large, independent Generation R study (see Luijk et al., 2011). 
Finally, to have additional confidence that inadequate reliability was not masking larger associations between the VNTRs examined in this report and attachment security and disorganization, we re-ran correlational and regression analyses on the sub-sample of cases that received identical genotypes on the first and second (i.e., reliability) round of genotyping. Of 24 relevant correlations (two VNTRs X two ethnic groups X three genetic models), only one non-significant effect in the full sample emerged as statistically significant ( $p<.05$, uncorrected) in the perfectly reliable sub-sample. Specifically, as reported in Table 2, the correlation between DRD4 48 bp VNTR homozygous versus heterozygous for the White sub-sample was $r=-.06, p=.19$. Focusing only on the subsample of cases that showed perfect reliability for the homozygous vs. heterozygous distinction on the DRD4 VNTR, the correlation in the White sub-sample was $r=-.12, p=$. 02 (uncorrected for multiple comparisons). All other correlations were nearly identical in magnitude in the perfectly reliable DRD4 and 5HTT VNTR sub-samples. Similarly, the results of the regressions involving the DRD4 and 5HTT VNTRs did not differ from the primary results we reported when we focused on the perfectly reliable subsamples (nonsignificant interactions remained non-significant and the one significant interaction between 5HTT and sensitivity in the prediction of disorganization remained statistically significant again, $p$-values uncorrected for multiple comparisons). ${ }^{6}$

Another issue that we should emphasize is that, in line with the observations noted above, Raby et al. (2012) refined their coding of the 5HTT VNTR by distinguishing individuals as A versus G on rs25531 SNP in the long allele of the 5HTT VNTR. We have not genotyped the rs25531 SNP in the SECCYD and therefore cannot know whether the results reported here would have differed had we done so. That said, we are in general skeptical of the claim that re-coding of this sort is likely to produce substantive changes in the results of any particular study of the serotonin transporter gene, for two reasons. First, the correlation between 5HTT coded with (i.e., tri-allelic) versus without (i.e., bi-allelic) attention to the rs25531 SNP is likely to be extremely high in most samples due to the low base rate of $l_{\mathrm{G}}$ carriers. For this reason, it is improbable that such a re-coding would result in the relevant association shifting from a significantly negative association (as in the White subsample of the SECCYD) to a significantly positive correlation (as in Raby et al., 2012). Second, it is important to emphasize that the functional equivalence of $l_{G}$ and $s$ is by no means a resolved issue and therefore should not be assumed (Martin, Cleak, Willis-Owen, Flint, \& Shifman, 2007).

One final caveat should be considered. Our focus here has been on highlighting what we view to be the serious limitations associated with genetic association studies relying on "usual suspect" polymorphisms, particularly in the small sample case. This does not mean, of course, that there have not been some notable successes where this approach has yielded replicable findings. There is consensus that certain SNPs in the apolipoprotein E (APOE) gene are correlated with increased risk for Alzheimer's Disease, for example, and such evidence emerged in genetic association studies. The problem, however, is that identifying

\footnotetext{
${ }^{6}$ In the perfectly reliable sub-sample (as in the larger sample), White infants in the high distress group were less likely to be carriers of the short form of the 5HTT VNTR than those in the low distress group (equivalent to an $r=-.09, p=.08$ ). The association was $r=$. $17, p=.13$ for non-White infants in the perfectly reliable sub-sample.
} 
in advance of empirical investigation the small set of psychological phenotypes that are likely to yield non-trivial associations with measured genetic variants has not been straightforward. Even relatively high heritability estimates, for example, seemingly provide little guidance: studies of general mental ability (i.e., intelligence) - a clearly heritable construct - have fared little better in identifying replicable genetic correlates using the genetic association approach (Chabris et al., 2012) than have the studies of infant attachment reviewed in this report. Indeed, a skeptical scholar might even question whether the genetic association approach is worth pursuing any longer in light of the expectation that many psychological phenotypes are massively polygenic. Importantly, alternatives exist, including the empirically-driven Genome Wide Association (GWA) approach. That said, GWA studies require extremely large samples, a challenge for developmental psychologists who study constructs - like attachment security and disorganization - that are oftentimes prohibitively expensive to measure with high levels of validity and reliability in the large $N$ context.

\section{Conclusion}

Based on the two largest studies of their kind - Generation R and the NICHD SECCYD (see also Luijk et al., 2011) - there is at present scant evidence that any specific SNP or VNTR measured to date is reliably associated with infant attachment security or disorganization. For this reason, the results of this study serve as a cautionary tale not only in terms of the importance of sample size and replicability, but also as a call for researchers investigating candidate gene markers to consider a reasoned approach to studying phenotypes for which evidence of genetic influence is more than minimal.

\section{Acknowledgments}

DNA extraction and genotyping for the NICHD SECCYD was performed at the Genome Core Facility in the Huck Institutes for Life Sciences at Penn State University under the direction of Deborah S. Grove, Director for Genetic Analysis. Genotyping was principally supported by a Research Board grant from the University of Illinois at Urbana-Champaign to Philip C. Rodkin and the first author. The NICHD SECCYD was supported by the Eunice Kennedy Shriver National Institute of Child Health and Human Development, the National Institutes of Health. We express our appreciation to the study coordinators at each site who oversaw the data collection, to the research assistants who collected the data, and especially to the families and children who cooperated so willingly with our longitudinal data collection.

\section{References}

Ainsworth, MS.; Blehar, MC.; Waters, CS.; Wall, S. Patterns of attachment: A psychological study of the Strange Situation. Oxford: Lawrence Erlbaum; 1978.

Anchordoquy HC, McGeary C, Liu L, Krauter KS, Smolen A. Genotyping of three candidate genes after whole-genome preamplification of DNA collected from buccal cells. Behavioral Genetics. 2003; 33:73-78.

Bakermans-Kranenburg MJ, Van IJzendoorn MH. No association of the dopamine D4 receptor (DRD4) and - 521 C/T promoter polymorphisms with infant attachment disorganization. Attachment \& Human Development. 2004; 6:211-218. [PubMed: 15513263]

Barry RA, Kochanska G, Philibert RA. G $\times$ E interaction in the organization of attachment: Mothers' responsiveness as a moderator of children's genotypes. Journal of Child Psychology and Psychiatry. 2008; 49:1313-1320. [PubMed: 19120710]

Belsky J, Pluess M. Beyond diathesis-stress: Differential susceptibility to environmental influences. Psychological Bulletin. 2009; 135:885-908. [PubMed: 19883141] 
Belsky J, Rovine M. Temperament and attachment security in the Strange Situation: An empirical rapprochement. Child Development. 1987; 58:787-795. [PubMed: 3608649]

Caspi A, Sugden K, Moffitt TE, Taylor A, Craig IW, Harrington HL, Poulton R. Influence of life stress on depression: Moderation by a polymorphism in the 5-HTT gene. Science. 2003; 301:386389. [PubMed: 12869766]

Chabris CF, Hebert BM, Benjamin DJ, Beauchamp JP, Cesarini D, van der Loos MJHM, Laibson D. Most reported genetic associations with general intelligence are probably false positives. Psychological Science. 2012; 23:1314-1323. [PubMed: 23012269]

Charney E, English W. Candidate genes and political behavior. American Political Science Review. 2012; 1:1-34.

Chen FS, Barth ME, Johnson SL, Gotlib IH, Johnson SC. Oxytocin receptor (OXTR) polymorphisms and attachment in human infants. Frontiers in Developmental Psychology. 2011; 2:1-6.

Cicchetti D, Rogosch FA, Toth SL. The effects of child maltreatment and polymorphisms of the serotonin transporter and dopamine D4 receptor genes on infant attachment and intervention efficacy. Development \& Psychopathology. 2011; 23:357-372. [PubMed: 23786683]

Cohen J. A power primer. Psychological Bulletin. 1992; 112:155-159. [PubMed: 19565683]

Fearon RMP, Van IJzendoorn MH, Fonagy P, Bakermans-Kranenburg MJ, Schuengel C, Bokhorst CL. In search of shared and nonshared environmental factors in security of attachment: A behaviorgenetic study of the association between sensitivity and attachment security. Developmental Psychology. 2006; 42:1026-1040. [PubMed: 17087539]

Fraley, RC.; Marks, MJ. The null hypothesis significance testing debate and its implications for personality research. In: Robins, RW.; Fraley, RC.; Krueger, RF., editors. Handbook of research methods in personality psychology. New York, NY: Guilford; 2007. p. 149-169.

Fraley RC, Roisman GI, Haltigan JD. The legacy of early experiences in development: Formalizing alternative models of how early experiences are carried forward over time. Developmental Psychology. 2013; 49:109-126. [PubMed: 22448982]

Fraley RC, Spieker SJ. Are infant attachment patterns continuously or categorically distributed? A taxometric analysis of Strange Situation behavior. Developmental Psychology. 2003; 39:387-404. [PubMed: 12760508]

Freeman B, Smith N, Curtis C, Huckett L, Mill J, Craig IW. DNA from buccal swabs recruited by mail: Evaluation of storage effects on long-term stability and suitability for multiplex polymerase chain reaction genotyping. Behavioral Genetics. 2003; 33:67-72.

Hu XZ, Lipsky RH, Zhu G, Akhtar LA, Taubman J, Greenberg BD, Goldman D. Serotonin transporter promoter gain-of-function genotypes are linked to obsessivecompulsive disorder. American Journal of Human Genetics. 2006; 78:815-826. [PubMed: 16642437]

Ioannidis JP. Genetic associations: False or true? Trends in Molecular Medicine. 2003; 9:135-138. [PubMed: 12727138]

Kochanska G, Aksan N, Knaack A, Rhines HM. Maternal parenting and children's conscience: Early security as moderator. Child Development. 2004; 75:1229-1242. [PubMed: 15260874]

Lakatos K, Nemoda Z, Toth I, Ronai Z, Ney K, Sasvari-Szekely M, et al. Further evidence for the role of the dopamine D4 receptor (DRD4) gene in attachment disorganization: Interaction of the exon III 48-bp repeat and the $521 \mathrm{C} / \mathrm{T}$ promoter polymorphisms. Molecular Psychiatry. 2002; 7:27-31. [PubMed: 11803443]

Lakatos K, Toth I, Nemoda Z, Ney K, Sasvari-Szekely M, Gervai J. Dopamine D4 receptor (DRD4) gene polymorphism is associated with attachment disorganization in infants. Molecular Psychiatry. 2000; 5:633-637. [PubMed: 11126393]

Lesch KP, Bengel D, Heils A, Sabol SZ, Greenberg BD, Petri S, et al. Association of anxiety-related traits with a polymorphism in the serotonin transporter gene regulatory region. Science. 1996; 274:1527-1531. [PubMed: 8929413]

Luijk MPCM, Roisman GI, Haltigan JD, Tiemeier H, Booth-LaForce C, Van IJzendoorn MH, et al. Dopaminergic, serotonergic, and oxytonergic candidate genes associated with infant attachment security and disorganization? In search of main and interaction effects. Journal of Child Psychology and Psychiatry. 2011; 52:1295-1307. [PubMed: 21749372] 
Main, M.; Solomon, J. Procedures for identifying infants as disorganized-disoriented during the Ainsworth Strange Situation. In: Greenberg, M.; Cicchetti, D.; Cummings, EM., editors. Attachment in the preschool years: Theory, research and intervention. Chicago: University of Chicago Press; 1990. p. 121-160.

Martin J, Cleak J, Willis-Owen SAG, Flint J, Shifman S. Mapping regulatory variants for the serotonin transporter gene based on allelic expression imbalance. Molecular Psychiatry. 2007; 12:421-422. [PubMed: 17453058]

Meehl PE. Theory-testing in psychology and physics: A methodological paradox. Philosophy of Science. 1967; 34:103-115.

Moonesinghe R, Khoury MJ, Janssens ACJW. Most published research findings are false - But a little replication goes a long way. PLoS Medicine. 2007; 4:e28. [PubMed: 17326704]

Munafò MR, Durrant C, Lewis G, Flint J. Gene $\times$ environment interactions at the serotonin transporter locus. Biological Psychiatry. 2009; 65:211-219. [PubMed: 18691701]

Muthén B, Asparouhov T, Rebello I. Advances in behavior genetics modeling using Mplus: Applications of factor mixture modeling to twin data. Twin Research and Human Genetics. 2006; 9:313-324. [PubMed: 16790142]

Neale, MC.; Cardon, LR. Methodology for genetic studies of twins and families. Boston, MA: Kluwer Academic Publishers; 1992.

NICHD Early Child Care Research Network. Early child care and self-control, compliance, and problem behavior at twenty-four month and thirty-six months. Child Development. 1998; 69:1145-1170. [PubMed: 9768491]

NICHD Early Child Care Research Network. Child care and child development: Results from the NICHD study of early child care and youth development. New York, NY: Guilford Press; 2005. Nonmaternal care and family factors in early development: An overview of the NICHD Study of Early Child Care; p. 3-36.

Pauli-Pott U, Friedl S, Hinney A, Bebebrand J. Serotonin transporter gene polymorphism (5HTTPLR), environmental conditions, and developing negative emotionality and fear in early childhood. Journal of Neural Transmission. 2009; 116:503-512. [PubMed: 19137235]

Raby KL, Cicchetti D, Carlson E, Cutulli JJ, Englund M, Egeland B. Genetic and caregiving contributions to infant attachment: Unique associations with distress reactivity and attachment security. Psychological Science. 2012; 23:1016-1023. [PubMed: 22829464]

Richters JE, Waters E, Vaughn BE. Empirical classification of infant-mother relationships from interactive behavior and crying during reunion. Child Development. 1988; 59:512-522. [PubMed: 3359869]

Rijsdijk FV, Sham PC. Analytic approaches to twin data using structural equation models. Briefings in Bioinformatics. 2002; 3:119-133. [PubMed: 12139432]

Risch N, Herrell R, Lehner T, et al. Interaction between the serotonin transporter gene (5-HTTLPR), stressful life events, and risk of depression. Journal of the American Medical Association. 2009; 301:2462-2471. [PubMed: 19531786]

Roberts S, Pashler H. How persuasive is a good fit? A comment on theory testing. Psychological Review. 2000; 107:358-367. [PubMed: 10789200]

Rodgers JL. The epistemology of mathematical and statistical modeling: A quiet methodological revolution. American Psychologist. 2010; 65:1-12. [PubMed: 20063905]

Roisman GI, Fraley RC. A behavior-genetic study of parenting quality, infant attachment security, and their covariation in a nationally representative sample. Developmental Psychology. 2008; 44:831839. [PubMed: 18473647]

Rutter M, Thapar A, Pickles A. Gene-environment interactions: Biologically valid pathway or artifact? Archives of General Psychiatry. 2009; 66:1287-1289. [PubMed: 19996033]

Sander T, Harms H, Dufeu P, Kuhn S, Rommelspacher H, Schmidt LG. Dopamine D4 receptor exon III alleles and variation of novelty seeking in alcoholics. American Journal of Medical Genetics. 1997; 74:483-487. [PubMed: 9342196]

Simmons J, Nelson L, Simonsohn U. False-positive psychology: Undisclosed flexibility in data collection and analysis allow presenting anything as significant. Psychological Science. 2011; 22:1359-1366. [PubMed: 22006061] 
Spangler G, Johann M, Ronai Z, Zimmermann P. Genetic and environmental influence on attachment disorganization. Journal of Child Psychology and Psychiatry and Allied Disciplines. 2009; 50:952-961.

Turkheimer E. Three laws of behavior genetics and what they mean. Current Directions in Psychological Science. 2000; 9:160-164.

Turkheimer E. Still missing. Research in Human Development. 2011; 8:227-241.

Uncles MD, Kwok S. Designing research with in-built differentiated replication. Journal of Business Research. 2012 Advance online publication. doi: http://dx.doi.org/10.1016/j.jbusres.2012.05.005.

Van IJzendoorn MH, Kroonenberg PM. Cross-cultural consistency of coding the Strange Situation. Infant Behavior and Development. 1990; 13:469-485.

Wacker J, Mueller EM, Hennig J, Stemmler G. How to consistently link extraversion and intelligence to the catechol-O-methyltransferase (COMT) gene: On defining and measuring psychological phenotypes in neurogenetic research. Journal of Personality and Social Psychology. 2012; 102:427-444. [PubMed: 22180998]

Zalsman G, Huang YY, Oquendo MA, Burke AK, Hu XZ, Brent DA, Mann JJ. Association of a triallelic serotonin transporter gene promoter region (5-HTTLPR) polymorphism with stressful life events and severity of depression. American Journal of Psychiatry. 2006; 163:1588-1593.

[PubMed: 16946185] 
Roisman et al.

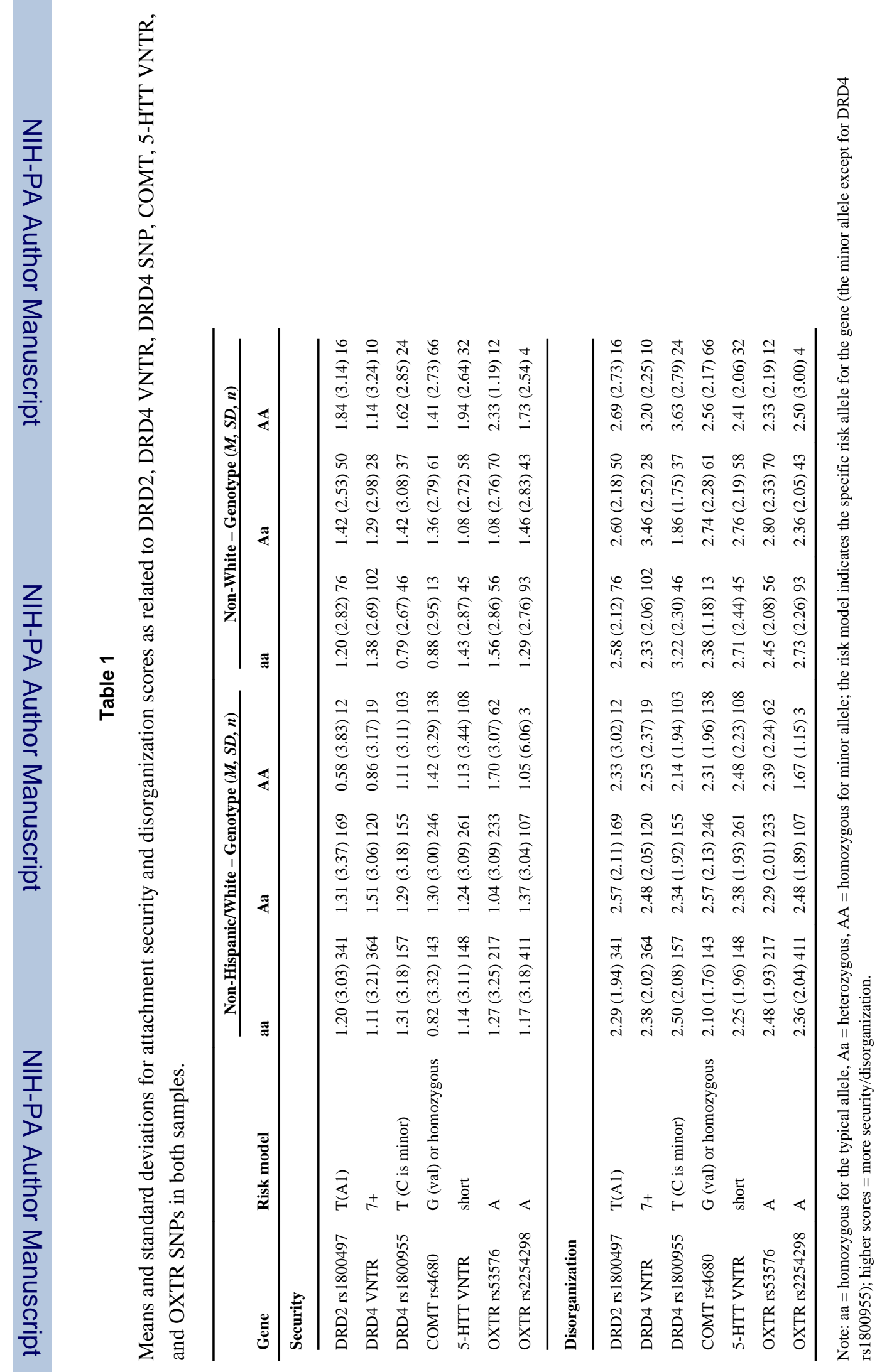

Attach Hum Dev. Author manuscript; available in PMC 2014 May 01. 


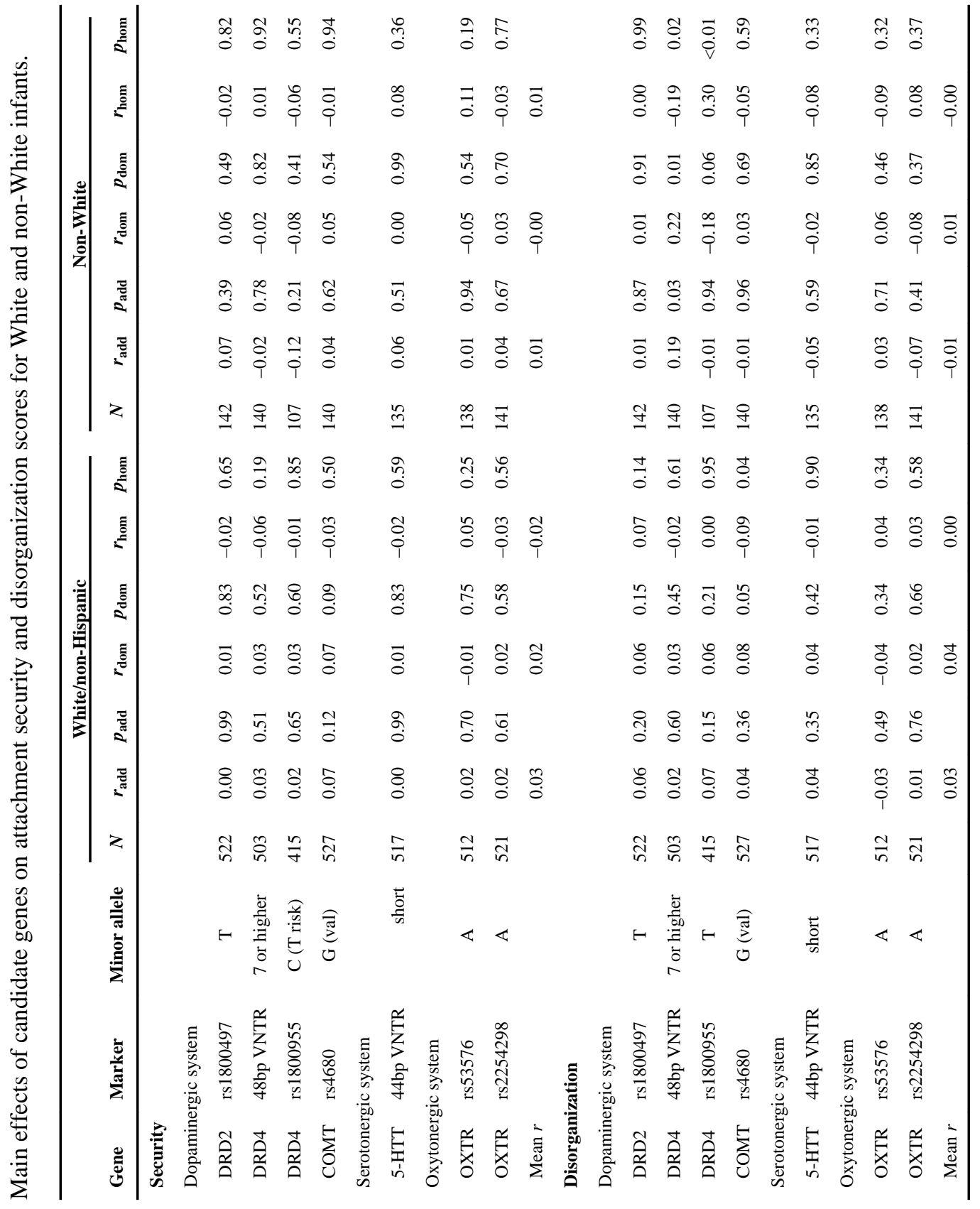




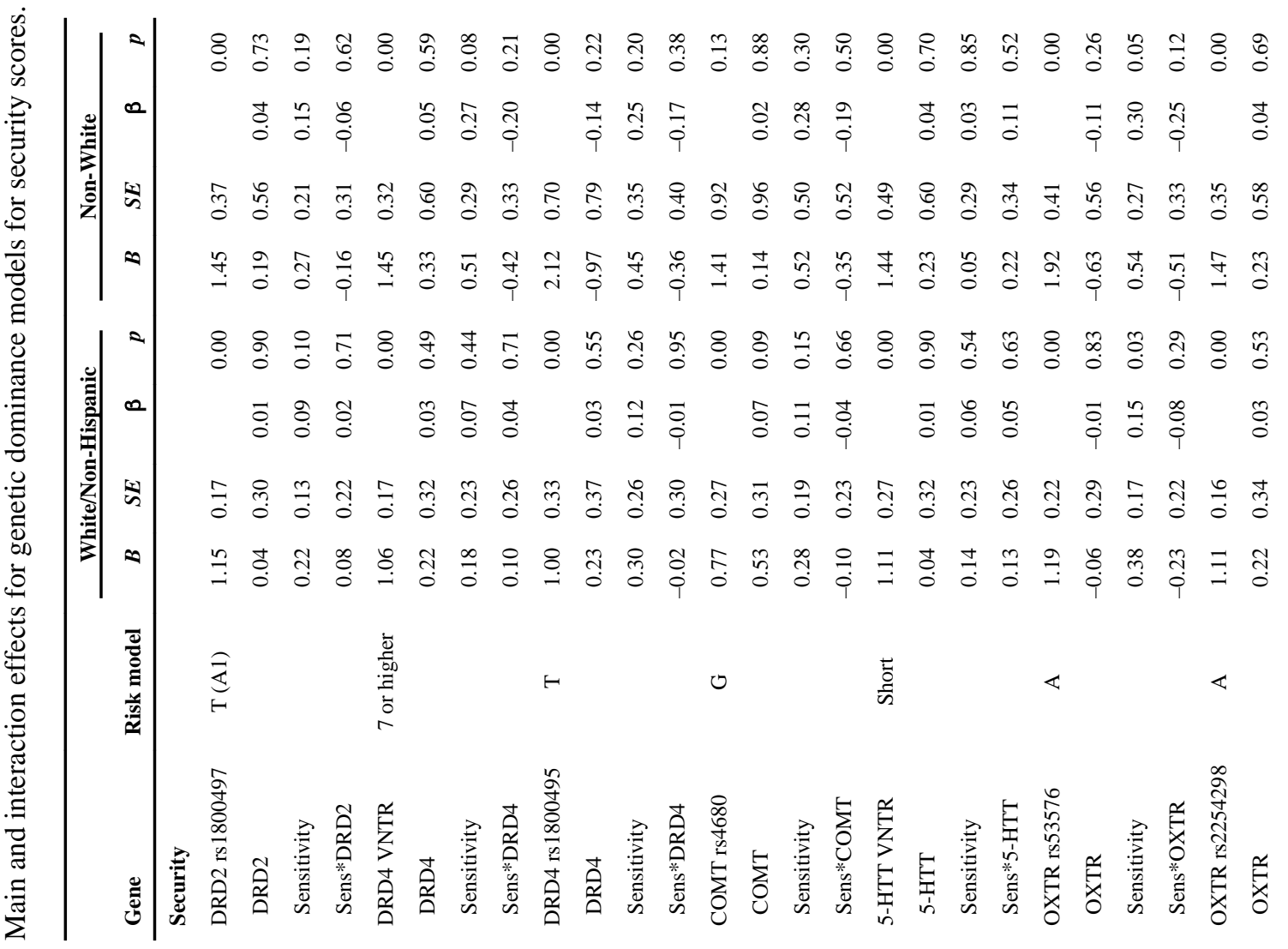




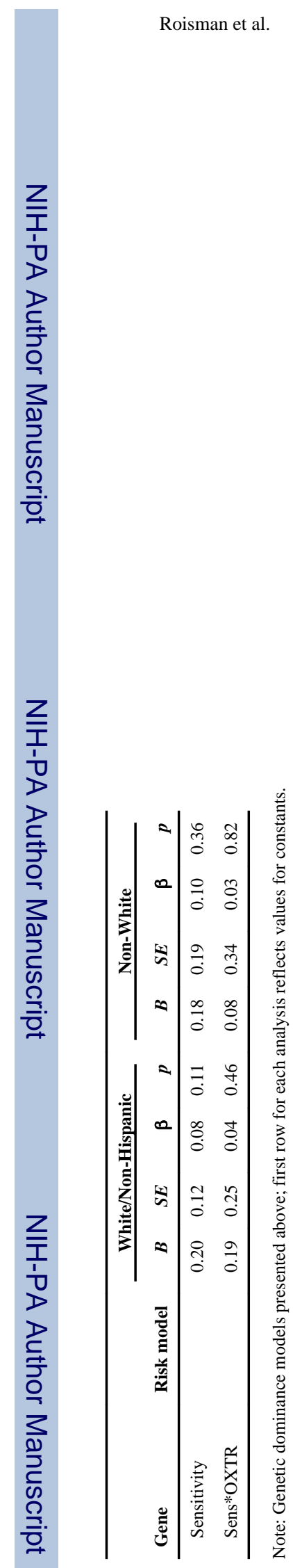

Page 24 


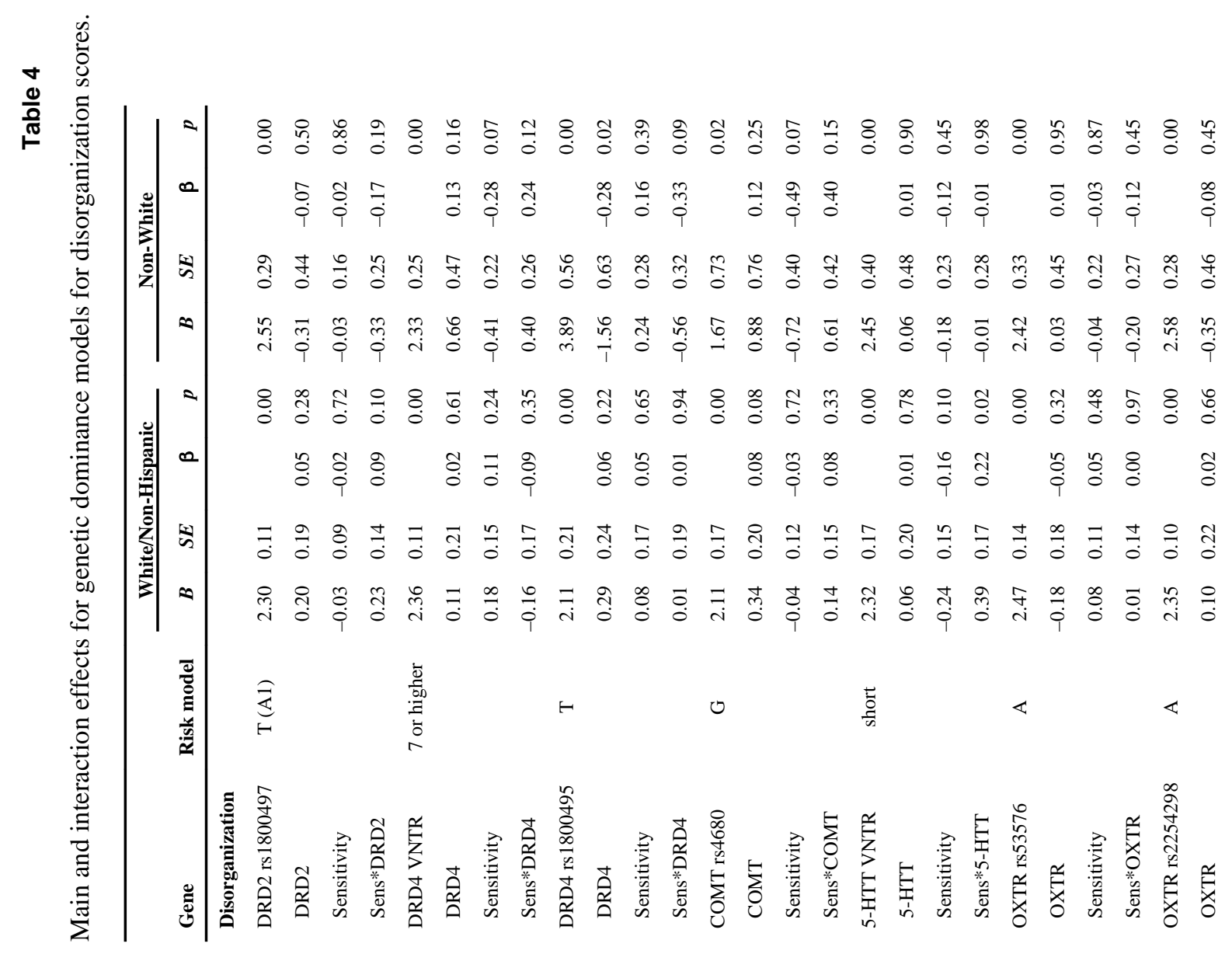




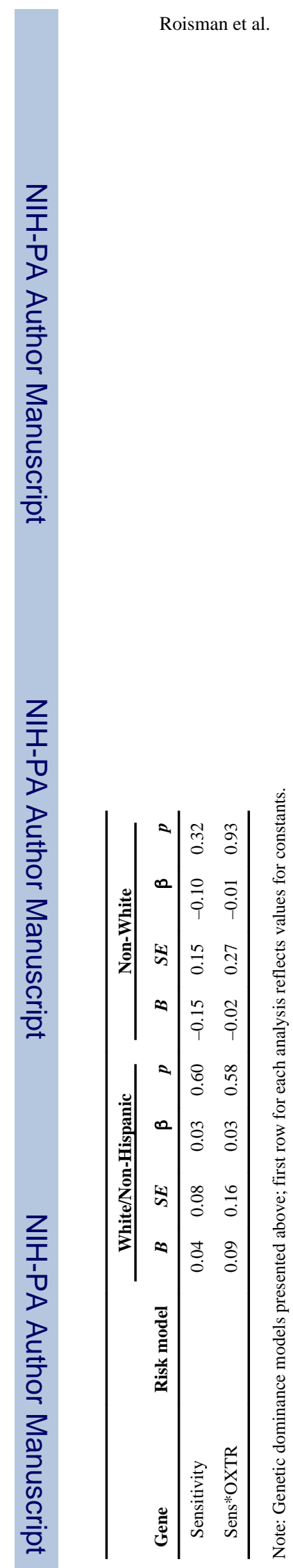

Page 26 